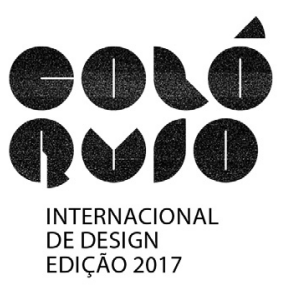

\title{
Por um design de vivências
}

\author{
Renato Bedore; \\ Marcos Beccari
}

resumo:

Este artigo apresenta um breve estudo exploratório com o objetivo de indicar algumas bases relacionais entre o conceito de vivência e o campo do design. Em outros termos, nosso intuito é fornecer subsídios a um design de vivências.

O estudo nos permitiu apontar as bases para o pensamento de um novo nicho do design, 0 design de vivências. Para tal, de início apontamos as definições do termo vivência, a partir de estudo desenvolvido sobre o pensamento do filósofo Friedrich Nietzsche, e a comparamos com a noção de experiência, passando por conceitos que somados geraram o entendimento da mesmo como sendo: um tipo de experiência de natureza estética, singular e intensamente afetiva, que se concretiza por conveniência. Em seguida, com base em uma breve análise de alguns modelos visuais desenvolvidos por outros autores apontamos para os mecanismos que formam uma vivência. $E$ por fim refletimos esses conceitos em uma possível práxis de um design de vivências.

\section{palavras-chave:}

Vivência; estética; experiência; design de serviços; 


\title{
1. Introdução
}

Este artigo busca discutir o tema da vivência no campo do design e apontar possíveis bases teóricas para o desenvolvimento de uma nova abordagem: um design de vivência. Tal abordagem se demostra promissora por estar em consonância com o crescimento do setor de serviços, mais especificamente na busca desse setor por experiências transformadoras que possibilitem um envolvimento estético-afetivo significativo.

Essa percepção pode ser recentemente ancorada nas indicações das tendências para o mercado de varejo para o ano de 2017, que surgiram no NRF Retail's Big Show (um dos maiores eventos de varejo do mundo). Dentre as principais indicações, podemos destacar a necessidade de focar em serviços mais próximos do cliente e que tenham como pressuposto o caráter singular-individual das experiências. Para isso é apontada a necessidade de provocar "imersões" por meio de experiências e vivências que abarquem todos os sentidos fisiológicos. Essa breve constatação ainda é fomentada pela noção do caráter potencializador que tais "imersões" têm em gerar relações mais próximas, tanto entre pessoas quanto entre pessoas e objetos (mundo), por meio de interações estéticas.

Para cumprir o objetivo central, de propor uma reflexão sobre algumas bases teóricas do campo da filosofia e relacioná-las ao campo do design como um meio fértil para o estudo de um design de vivências, é preciso pontuar o recorte epistemológico em que se situa tal discussão. Trata-se do prisma poético que enquadra o design como uma dimensão criadora da estética, caracterizando-o como articulador de afetos. Essa visão pode ser pautada pelo segundo eixo da Filosofia do Design: Design e sensibilidades, que parte da premissa segundo a qual o registro estético/afetivo é constitutivo na relação dos humanos com o mundo.

\begin{abstract}
Neste eixo, o design é encarado em sua dimensão de veiculador de afetos. [...] Tal dimensão não redutível à linguagem envolve o que poderíamos chamar de estética, como a caracterização nietzscheana das pulsões estéticas (apolínea e dionisíaca) que, por intermédio de sua interpretação posterior sobre "arte", pode se mostrar fecunda para pensarmos em nossas ações e intenções não mais sob o registro paradigmático das necessidades e das utilidades. (BECCARI, 2016, p. 53)
\end{abstract}

Portanto, o caminho a ser traçado para a proposição da vivência como um "objeto" do design partirá da premissa que a identifica como um fenômeno de natureza estético-afetiva. Tal raciocínio será desenvolvido a partir do entendimento da semântica do conceito de Erlebnis ("vivência", aqui encarada pela ótica do filósofo alemão Friedrich Nietzsche) em comparação com o conceito de Erfahrung ("experiência"). Por fim, serão propostas possíveis relações entre a noção de vivência e a de um design de vivências.

\section{Vivência}

A palavra "vivência" pode ser relacionada à etimologia da palavra alemã Erlebnis que, de acordo com Jorge Viesenteiner (2013), em seu artigo O conceito de vivência (Erlebnis) em Nietzsche, teve suas primeiras ocorrências na primeira metade do século XIX. O autor define o significado do termo alemão da seguinte forma: "[...] substantivado a partir do verbo erleben, Erlebnis significa 'estar ainda presente na vida quando algo acontece' [...]" (VIESENTEINER, 2013, p. 2). Somadas a essa noção, Mileck (2016) apresenta mais duas definições sobre o termo Erlebnis: "experiência" e "emoção". Os autores espanhóis Morente e Bengoechea (1970, p. 1) a definem como sendo o significado do que "[...] temos realmente em nosso ser psíquico, o que real e verdadeiramente estamos sentindo, tendo (na plenitude da palavra 'ter')".

Dessa forma, se fôssemos reduzir a tradução de Erlebnis para o português em uma palavra, ela poderia ser "vivência", cuja primeira definição seria o momento no qual nos sentimos vivos por meios dos nossos sentimentos e emoções, ou seja, pela via estética. "Do grego aisthesis ou aestesis, estética significa a capacidade de sentir o mundo, compreendê-lo pelos sentidos, é o exercício das sensações" (ALMEIDA, 2015, p. 134). Para uma maior compreensão sobre o que a vivência significa, tomemos um exemplo apresentado por Bergson: 
Uma pessoa pode estudar minuciosamente o mapa de Paris; estudá-lo muito bem; observar um por um os diferentes nomes das ruas; estudar suas direções; depois pode estudar os monumentos que há em cada rua; pode estudar os planos desses monumentos; pode revistar as séries das fotografias do Museu do Louvre, uma por uma. Depois de ter estudado o mapa e os monumentos pode este homem procurar para si uma visão das perspectivas de Paris mediante uma série de fotografias tomadas de múltiplos pontos. Pode chegar dessa maneira a ter uma ideia bastante clara, muito clara, claríssima, pormenorizadíssima, de Paris. Semelhante ideia poderá ir aperfeiçoando-se cada vez mais, à medida que os estudos deste homem forem cada vez mais minuciosos; mas sempre será uma simples ideia. Ao contrário, vinte minutos de passeio a pé por Paris são uma vivência. (BERGSON apud MORENTE; BEGOECHEA, op. cit., p. 1-2)

$\mathrm{Na}$ fala de Bergson, fica clara a diferença entre a compreensão da cidade de Paris por via intelectual (no estudo de livros, fotos e mapas) e a compreensão sensível da cidade (ao se estar presente nela). Enquanto a primeira possibilita apreender os pormenores das principais características de Paris, na segunda essa compreensão seria parcial e subjetiva, por via das sensações e emoções que são geradas no momento em que se está presente na cidade. Dessa forma, podemos inferir que só seria possível vivenciar Paris presencialmente. Tal conclusão remete à definição de vivência encontrada por Mileck no dicionário da Real Academia Española em sua versão on-line: o fato de viver ou experimentar algo (apud MILECK, 2016, p. 31).

A semântica da Erlebnis é apresentada por Veisenteiner (2013) a partir dos pensamentos de Friedrich Nietzsche e com base em três significados-chave referentes aos momentos formativos da vivência: plenitude; imediatez e significabilidade.

A plenitude se refere, principalmente, ao atributo que caracteriza a vivência como sendo algo imanente, ou seja, que se refere apenas a si mesmo. Ela seria plena pois nela existiriam todas as condições necessárias para a sua concretização. Dessa forma, não haveria a necessidade de uma causa ou estímulo, tampouco elementos pressupostos que a fomentem. Além disso, esse atributo seria o responsável pela definição do carácter estético da vivência, ao relacionar a plenitude com a compreensão da mesma por via dos sentidos ("estar imerso").

O segundo aspecto semântico da vivência seria a imediatez, que se refere à ligação imediata do sujeito com o conteúdo da vivência. Seu início se daria no momento em que o sujeito é abarcado pela intensidade dos sentidos.

O atributo da significabilidade (não confundir com "significação") encerra a tríplice semântica da vivência, e se refere ao conteúdo afetivo da vivência. Segundo essa característica, para que ocorra a vivência é preciso que os afetos provocados pelas sensações sejam significativos e, dessa forma, provoquem uma mudança intensa no indivíduo. Tal intensidade deve chegar ao "[...] ponto de conferir importância decisiva ao caráter global da vida daquele que vivencia" (VIESENTEINER, 2013, p. 3).O autor ainda acrescenta que:

A vivência de algo não pode ter seu conteúdo construído racionalmente, mas antes deve ser unicamente experimentado, ou melhor, "sentido na pele", como evoca a expressão no português. A dimensão estética da Erlebnis está em plena sintonia com as duas características anteriores de 'imediatez' e 'significabilidade'. Erlebnis, 'sofrer na pele', alude à presença imediata de alguém que vivencia algo efetivamente, bem como se refere ao caráter estritamente individual de toda vivência, representando, por isso, a significabilidade para aquele que vivencia. Toda vivência é sempre "minha" vivência exclusivamente individual, e isso significa "não apenas que eu sinto, mas também que eu incondicionalmente sinto". (idem, 2013, p. 4)

Seguindo esse raciocínio, a vivência passaria a ser entendida como uma manifestação estética singular, plena (estética e afetivamente), imediata (como uma ligação direta com o mundo) e significativa (em conteúdo e na sua relação com a experiência acumulativa do indivíduo).

Para reforçar a compreensão do significado de vivência, convém estabelecer uma comparação 
com o conceito de experiência; isso porque muitas vezes os dois conceitos teriam suas bases semânticas confundidas. O critério a ser utilizado para isso ainda é o da língua alemã, dessa vez na comparação entre o significado da palavra Erlebnis com a palavra Erfahrung.

Em alemão existem ao menos duas palavras para o termo "experiência": Erfahrung, que tem mais a ver com experiência adquirida, aprendizagem pela prática, conhecimento adquirido na vida (e não nos livros); e Erlebnis, que tem uma conotação mais ligada à emoção sentida diante de um acontecimento concreto. [...] [a primeira definição deriva do verbo erfahren] que significa aprender, vir a saber, descobrir, experimentar, que é uma derivação do verbo 'fahren', que significa viajar, ir [...] [já a segunda deriva do substantivo erleben] que significa vivenciar, passar por, presenciar, que tem em sua raiz o substantivo leben, que significa vida. (MILECK, 2016, p. 33)

De um lado, Erfahrung se refere a uma experiência acumulativa e prática; de outro, Erlebnis indica uma experiência momentânea e estética. Ainda seguindo a diferenciação entre vivência e experiência, Viesenteiner (2013) afirma que a experiência teria um significado prático-moral, ou seja, é categorizada e analisada após se concretizar na prática e passar por um filtro moral; já a vivência teria um significado contrário e seria vista como algo estético-individual, que só acontece com uma pessoa de forma singular.

Com efeito, poderíamos inferir que a experiência teria um caráter coletivo, sendo possível que mais de uma pessoa possa "experenciar" de maneira similar determinado fenômeno. Por exemplo: visitar Paris pode remeter, por consenso, a uma experiência romântica e nostálgica, ao passo que pegar o metrô parisiense em "horário de rush" pode gerar uma vivência bem diferente. Isso porque a vivência estaria relacionada a situações e circunstâncias que dificilmente se repetiriam com exatidão, de modo que cada uma das pessoas que já esteve em Paris poderia ter tido uma vivência completamente diferente da outra.

Essa relação entre experiência e vivência já foi desenhada por alguns autores em forma de modelos esquemáticos. A seguir, discutiremos brevemente sobre dois modelos que foram retirados da pesquisa de Jannie Lindström (2009), Meeting room design based on experience production and creative process.

O primeiro modelo é baseado nos entendimentos de Snel (apud LINDSTRÖM, 2009) sobre os mecanismos de vivência (Erlebnis) e experiência (Erfahrung). Para o autor, a vivência seria vista como um evento isolado e imediato; já a experiência seria um "[...] processo contínuo de fazer e experimentar, dar e receber, causas e consequências, ações e reflexões, etc." (idem, p. 38.), conforme diagramas abaixo:
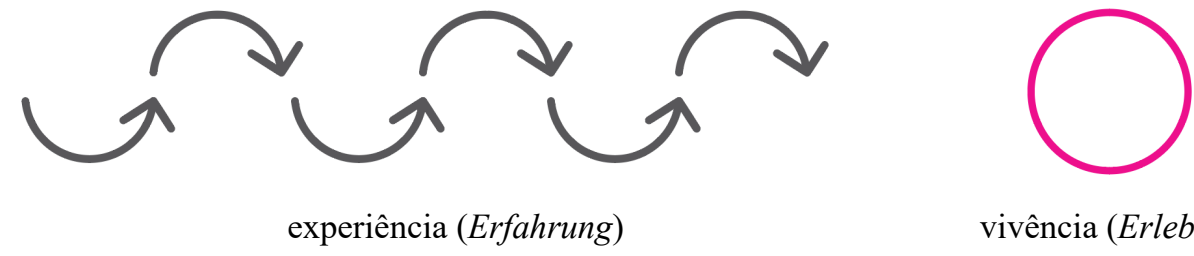

vivência (Erlebnis)

Figura 1. Mecanismo Erfahrung X Erlebnis. Fonte: Adaptado de SNEL apud LINDSTRÖM, 2009, p. 39.

O que parece ficar claro na relação desenhada acima é a diferença no mecanismo que constitui cada um dos fenômenos: enquanto a experiência seria uma soma de eventos contínuos, a vivência seria uma ocorrência isolada. Vale pontuar que essa relação ainda não se direciona para uma distinção efetiva dos dois conceitos no que diz respeito a suas naturezas.

$\mathrm{O}$ segundo modelo é proposto pela própria Lindström e define a vivência como uma ocorrência entre diferentes níveis de experiência. Desse ponto de vista, a vivência seria uma ocorrência que transformaria a experiência "1.0" em uma experiência " $2.0 "$ ". Mileck traduz a explicação desse modelo da seguinte forma:

Segundo o modelo de Lindström (2009), assim como um estudante em uma aula, cada 
vivência (Erlebnis) acontece com uma experiência de vida anterior (pré-experiência ou Erfahrung 1.0) originando uma nova maneira de se relacionar com o mundo, gerando então uma experiência de vida estendida (pós-experiência ou Erfahrung 2.0). Desta forma, não podemos ganhar experiências de vida (Erfahrung) sem algum tipo de vivência (Erlebnis), que segundo Lindström pode ocorrer em "graus diferentes" e pode ser "um evento no mundo real ou alguma experiência interna imaterial através do pensamento, sonhos e emoções". (MILECK, 2016, p. 43)

Nesse raciocínio, a vivência se relacionaria com a experiência seguindo o seguinte mecanismo:

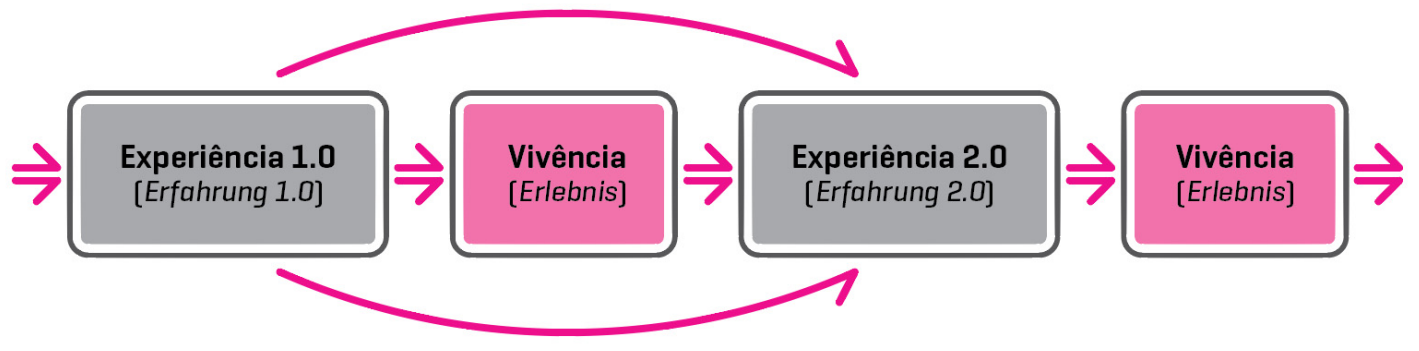

Figura 2. Processo entre experiências e vivências. Fonte: Adaptado de LINDSTRÖM apud MILECK, 2016, p. 43

Essa dinâmica localiza a vivência como um processo intermediário da experiência: entre um processo convencional e irrefletido em seu estágio inicial (experiência 1.0) e a compreensão do mesmo dentro de uma experiência acumulada (experiência 2.0). Existiria um elemento estético que promove tal mudança. Nesses termos, um exemplo de vivência é o recurso narrativo, amplamente explorado na literatura, dramaturgia e cinema, do in media res, isto é, quando o enredo inicia com uma cena localizada no meio da história. Esse corte inicial (descontextualizado a princípio) funciona como peça-chave para algo que acontecerá adiante, de modo a "amarrar" o que até então se apresenta de modo desconexo na história. Assim como a vivência, essa peça-chave promove uma compreensão mais coesa por meio de uma nova perspectiva em relação ao que aconteceu antes.

De imediato, se alinharmos esse exemplo com o mecanismo de relação das vivências com as experiências, apresentado por Lindström (2009), podemos dizer que havia uma experiência (convencional e irrefletida) prévia e que, após o sujeito ter sido afetado de modo intenso por uma vivência (estética e singular), sua experiência foi "atualizada".

Entretanto, surge a seguinte questão: até que ponto o que acontece na vivência se diferencia efetivamente dos mecanismos básicos da experiência? Sendo esta entendida como um processo de experimentar e receber algo por meio de ações e reflexões, como apresentou Snel (2005). O que ocorre na vivência é também uma experiência, porém com maior intensidade e plenitude estéticas, ou seja, conferindo uma signficabilidade necessária para caracterizar tal ocorrência como uma vivência. Logo, a vivência poderia ser tratada como uma experiência com maior intensidade estética.

Sendo a vivência, como vimos até aqui, um tipo de experiência estética singular, plena, imediata e significativa, cabe ainda verificarmos suas possíveis relações com o conceito de experiência de Jorge Larrosa (2014) e com o de experiência estética de Rogério de Almeida (2015).

Para Larrosa, o conceito de experiência mantém-se nebuloso, por consequência da falta de definições precisas que abarquem essa ideia como um todo. Entretanto, ele define a experiência significativa como sendo aquilo "[...] que nos passa, o que nos acontece, o que nos toca. Não o que se passa, não o que acontece, ou o que toca" (Larrosa, 2002, p. 2). Dessa forma, haveria uma separação entre os acontecimentos corriqueiros do dia-a-dia, e as experiências significativas que acontecem conosco. Por este caminho, o autor classifica a experiência como sendo algo que não pode ser planejado, apenas "provocado". Segundo essa ótica, ele afirma que ela seria uma "abertura ao desconhecido", isto é, àquilo que ainda não foi explorado ou mesmo "codificado". Ao que parece, pois, esse conceito está mais próximo da ideia apresentada anteriormente de vivência (erlebnis) do que da ideia de experiência (erfahrung). 
Para Rogério de Almeida, que parte do estudo de uma estética da experiência, esta seria a forma pela qual nos relacionamos diretamente com o mundo, um meio de intensificar nossa adesão à vida. Ele também segue na compreensão da experiência como algo singular ao afirmar que:

Não se pode prever onde e quando a experiência vai acontecer, mas pode-se estar mais ou menos aberto a ela, mais ou menos disponível, porque a experiência é o que nos passa, é o que nos afeta, é o que nos marca e depende sempre do encontro entre uma pessoa e uma ocasião, entre uma pessoa e um objeto, entre uma pessoa e outra pessoa. A experiência não é suscetível, portanto, ao controle. Pode-se buscar a ocasião, dedicar-se ao uso e à apreciação de um objeto, caçar paixões, entregar-se a pessoas, mas nenhuma dessas disposições é garantia de experiência. (ALMEIDA, 2015, p. 141)

Mais uma vez o conceito de experiência, agora com a característica principal de ser uma ocorrência estética, se aproxima da ideia de vivência. Sendo assim, é possível concluir que a vivência pode ser entendida como um tipo peculiar de experiência. Mais precisamente, trata-se de uma experiência estética, fugindo da acepção comum de "experiência" como sendo o acúmulo de saberes práticos - como o seu significado na frase "tenho mais de 10 anos de mercado, sou um profissional com experiência", aproximando-se mais do significado aludido numa expressão como "aquilo foi uma experiência incrível". Tal conotação se mostra alinhada à semântica da Erlebnis apresentada no início desse tópico, e reforçada no seguinte trecho:

Expressar algo através das Erlebnisse pressupõe revelar algo daquilo que alguém efetivamente sentiu e, neste aspecto, a dimensão estética da Erlebnis "não é apenas uma forma de Erlebnis ao lado de outras, mas ela representa a forma essencial de toda Erlebnis em geral" (VIESENTEINER, 2013 p. 4-5).

O que Viesenteiner parece indicar é que a relação da estética com a vivência está em nível de pressuposto e não de atributo. Ou seja, toda vivência é estética por estar em primeiro lugar ligada com a nossa adesão sensível ao mundo. Outra indicação trazida pelo autor, que se pauta nos dizeres de Nietzsche, é o entendimento de que a vivência sempre ocorre "ao acaso". Esse mecanismo fica claro no seguinte trecho da Aurora de Nietzsche:

Mal conseguirá dar o nome dos mais grosseiros a eles: o número e a intensidade deles, o fluxo e refluxo, o jogo recíproco e, sobretudo, as leis de sua alimentação, permanecem inteiramente desconhecidas para esse alguém. Esta alimentação será também obra do acaso: nossas vivências diárias lançam uma presa ora a esse, ora àquele impulso, que é avidamente apanhada, mas todo o ir-e-vir desses eventos está fora de qualquer nexo racional com as necessidades de nutrição da totalidade dos impulsos. [...] Nossas experiências, como disse, são todas, neste sentido, meios de alimentação, mas distribuídos com a mão cega [...] (NIETZSCHE, 2004, p. 119).

O que parece ficar claro nessa citação é também o caráter impalpável da vivência, sendo ela um resultado de conjunturas que são difíceis de se localizar e prever. Ademais, reforça o entendimento da imanência da vivência, que encontra a sua "forma" e "função" em sua própria manifestação. Essa ideia está próxima do conceito grego de kairós, defendido pelos sofistas, e que se refere à um "[...] momento oportuno, ocasião" (BECCARI, 2016, p. 215). Ou seja, a "mão cega" apontada como responsável por dar sentido às nossas vivências pode ser entendido como o próprio acaso. Porém, não um acaso ligado a conceitos metafísicos (como "Deus" ou "Natureza"), e sim à simples ocorrência da vivência que, por conveniência, se manifesta em um determinado momento oportuno, conforme esclarece o filósofo Mário Perniola:

[...] é somente em Górgias que a ligação entre conveniente e ocasião se emancipa daquele significado místico, referido à harmonia do cosmo, que a palavra kairós possuía originalmente, o problema da linguagem e de seu poder de sedução (apáte). "A palavra, como o pregão que é proclamado em Olímpia, convida quem quer, cora quem 
é capaz". Mas por que o resplandecer deve ter mais apáte, maior poder de sedução e, portanto, maior êxito? A resposta de Górgias é drástica: não existe prépon, não existe resplandecente que não seja conveniente, isto é, que não tenha essa adequação à ocasião, essa força de sedução para impor-se e triunfar. (PERNIOLA, 2000, p. 244245)

A proposição de Górgias (sofista grego) ao relacionar as ideias de resplandecer (prépon) e a de conveniência (kairós) é a de que o acaso se trata de uma ocasião não calculada. Essa noção se aproxima ainda mais dos conceitos de vivência apresentados até aqui, pois a intensidade dos afetos é singular e parece não existir meios de prever ou controlar as variáveis que caracterizam determinado momento como sendo pleno.

Cabe ainda destacar que essa dimensão ligada ao acaso também diz respeito à conexão de sensações menos intensas, oriundas de experiências anteriores de menor importância, e que se associam às sensações da vivência de modo a pleitear significado pleno. É como se a vivência provocasse uma "ligação entre os pontos" que antes passaram despercebidos por nós.

Como resultado da breve digressão traçada até aqui, propomos a noção de vivência como um tipo de experiência (dentre tantos outros que abrangem o termo) de natureza estética, singular e intensamente afetiva, concretizando-se por conveniência. Após a sua ocorrência por via estética, conferimos significado ao seu conteúdo e a um conjunto de experiências cotidianas, que antes não eram vistas como ocorrências intensas e plenas e não apresentavam ligação imediata entre si.

De maneira esquemática, poderíamos compreender o mecanismo da vivência por meio da representação abaixo (Fig. 3), que apresenta três (podendo ser mais ou menos) experiências comuns que, em primeira instância, não apresentam nenhuma conexão entre si. Por exemplo: ir comprar pão em uma padaria diferente da habitual (EX|1), assistir um assalto acontecer na sua frente (EX|2) e queimar a língua com um prato servido ainda quente (EX|3). Em um segundo momento, temos uma quarta experiência, mais carregada de intensidade afetiva (ou seja, uma vivência), que ocorre ao acaso e provoca uma compreensão mais coesa em consonância com as demais experiências. Um exemplo possível seria a leitura de um poema qualquer $(\mathrm{EX} \mid 4)$ que, através de um processo de reorganização dos significados das sensações, realiza e conjuga um significado pleno e imediato.

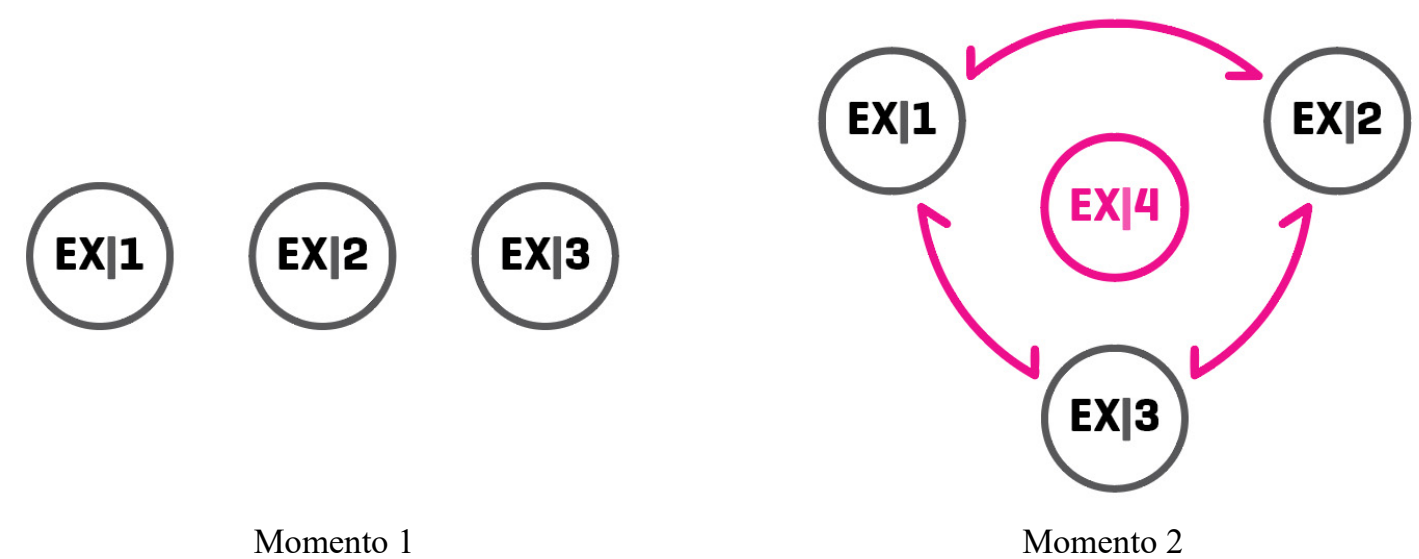

Figura 3: Relação entre experiências e vivências. Fonte: Elaborado pelos autores (2017).

\section{Design de vivências}

O termo design de vivências ainda não é utilizado de maneira ampla no meio acadêmico. Muito disso parece estar ligado ao caráter subjetivo e impreciso que a vivência carrega. Mas também parece existir uma relação com o modo pelo qual a maioria dos designers compreende a arte e a estética, conforme argumenta Marcos Beccari no trecho abaixo:

Ao que tudo indica, pois, a ideia que os designers fazem sobre a arte é aquela 
que alude a um Belo transcendente, a uma "estética desinteressada" como algo à parte do mundo concreto - leitura que se inicia em Platão, acentua-se em Kant e mantém-se intacta no idealismo alemão, na teologia negativa e na teoria crítica. (BECCARI, 2016, p. 206)

Pensar nos elementos estéticos em termos de representação de um belo transcendente, que reporta a uma verdade absoluta de beleza, parece limitar a compreensão sobre o que a própria estética se refere e, por conseguinte, a compreensão sobre o design de vivências. Tal restrição da estética à questão do belo é recorrente no design e se soma a pensamentos comprometidos com a noção de utilidade. Para Bernd Löbach, por exemplo, a estética estaria ligada a uma função dos objetos, e seria o resultado dos mecanismos psicológicos "[...] da percepção sensorial durante o seu uso" (LÖBACH, 2001, p. 60). Parece um tanto reducionista, sob o viés aqui proposto, pensar a vivência como um produto que tenha uma função de utilidade, assim como identificar nela as características estéticas relacionadas a tal função, ou ainda pensá-la a partir de uma função simbólica (ou convencional), uma vez que a vivência é uma experiência momentânea e singular, ou seja, não passível de repetição e padrões de reconhecimento.

Outra linha do design que relaciona utilidade e estética, e que também parece estar distante da vivência, é aquela preconizada por Donald Norman, que enxerga o design como uma ferramenta estratégica para lidarmos com nossos processamentos emocionais. Segundo esse pensamento, estaríamos ligados a nossas emoções por três níveis: visceral, comportamental e reflexivo. O primeiro seria o nível mais rudimentar do cérebro humano, sendo responsável pela percepção das emoções naturais, como por exemplo a sensação agradável ou desagradável provocada por determinados gostos ou cheiros. O segundo nível, o "comportamental", estaria diretamente relacionado às sensações provocadas pelo uso dos objetos, considerando "função, facilidade de compreensão sobre o produto, usabilidade e a forma como ele é fisicamente sentido" (TONETO; COSTA, 2011, p. 139). O terceiro e último nível se refere a emoções ligadas a uma cultura, um significado ou uma memória.

Nota-se que as próprias emoções humanas são encaradas, nesse modo de classificação, como "funções" cognitivas, isto é, como processos à serviço da percepção e compreensão das coisas. A dimensão estética, sob esse viés, aparece como uma função confusa, primitiva, antiquada. E sendo as vivências um tipo de experiência estética, de modo geral elas seriam classificadas como algo não útil sob o prisma desse pensamento recorrente no campo do design: estética como um atributo secundário de objetos e serviços que tenham uma forma e uma função pré-estabelecida.

De maneira esquemática, poderíamos pensar que, há algumas décadas, a visão predominante nas escolas e centros de design baseava-se num discurso funcionalista segundo o qual a forma das coisas deveria ser subordinada a uma função previamente dada: uma cadeira deve ser projetada para servir de assento; um carro, para se locomover; um cartaz, para comunicar claramente uma mensagem etc. (BECCARI, 2016, p. 26)

Analisando por essa linha de raciocínio, podemos compreender com mais clareza a lacuna de estudos sobre design e vivências: se não for possível conferir uma utilidade a uma vivência, não haveria motivos para nos preocuparmos com ela. Porém, esse pensamento pragmático aparentemente vem perdendo força. "O que o design tem trazido ao primeiro plano nos dias de hoje é o fato de que uma relação vale pela própria relação, que a 'aparência' das coisas vale pela própria aparência" (idem), ou seja, o design tem abrangido muito mais questões do que simplesmente a funcionalidade objetiva dos produtos e serviços. É possível pensar o design como sendo um meio de articulação estética de nós conosco mesmos e com o mundo, ou seja, um mediador de elementos estéticos, ou ainda "[...] como um modo de compreender que vale mais pela forma de enunciação, expressão, adequação e retórica (dimensão estética) do que pela possibilidade de seguir funções ou de resolver problemas que estariam "além das aparências"" (ibidem). Nesse ponto de vista, existe a possibilidade de pensar o design de vivências como um meio para entender as manifestações desse modo de compreender, assim como o impacto que o mesmo pode gerar em nossa experiência cotidiana.

O que se cria no design, em sua articulação simbólica, depende mais do "representar" 
em si, no sentido de reconfiguração e rearranjo das coordenadas disponíveis, como uma espécie de caleidoscópio que produz sempre uma nova combinação a partir de si mesmo. Em outras palavras, cria-se mais a partir da captura e do agenciamento e menos a partir da descoberta ou da invenção; o desafio não é tanto ter uma ideia, e sim conseguir expressá-la, conferir-lhe uma forma. (ibidem, 2016, p. 236-237)

É partindo desse ponto de vista, do design como uma articulação simbólica, que nos parece ser possível pensar o design de vivências. Sendo elas, como vimos anteriormente, de natureza estética e sem uma consequência prevista, não cabe pensá-las como uma ferramenta para atingir uma função.

A título de analogia didática, podemos comparar as vivências com o mecanismo de um trovão. Por ser um fenômeno que envolve fatores naturais diversos, não podemos "desenhar" ou "projetar" um trovão, para que ele ocorra da exata maneira que gostaríamos, mas é possível estimular a sua ocorrência e até guiar o seu local de queda por meio de um para-raios. Algo similar parece ser possível de ser feito com a vivência, após a compreensão dos aspectos estéticos que a provocam. Parece ser possível analisar tais mecanismos e pensar em meios de provocar seu acontecimento através de experiências projetadas (passíveis de repetição), que poderiam propiciar ou estimular a ocorrência dos aspectos caracterizadores da vivência, mas não há como garantir que uma vivência aconteça.

Com o objetivo de sintetizar os mecanismos da vivência de forma esquemática, apresentamos a seguir (Fig. 5) uma representação dos principais pontos definidores desse fenômeno. De início, fica compreendido que a vivência ocorre na relação homem-mundo (seja com objetos, situações ou até com outros homens). Sua ocorrência está a mercê do acaso, ou seja, acontece sem previsão e de maneira imediata e impalpável (análoga ao trovão). A compreensão de tal fenômeno é singular e individual, sendo "sentida na pele", portando de natureza estética. Da sua ocorrência derivam duas "consequências", uma interna que impacta o indivíduo pela sua intensidade afetiva, e outra externa que promove uma intensificação da adesão do indivíduo à vida:

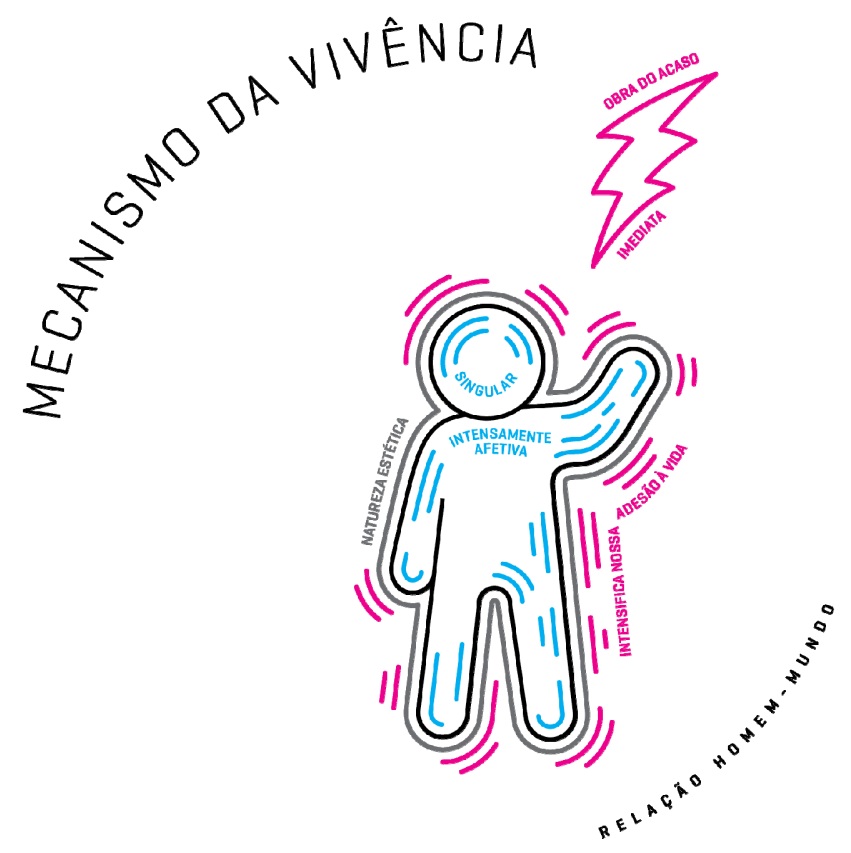

Figura 4: Mecanismo da vivência. Fonte: Elaborado pelos autores (2017).

Para ficar ainda mais claro esse processo, podemos pegar um exemplo retratado no terceiro episódio da serie documental Abstract: The Art of Design, denominado de ES Devlin: Cenógrafa. Tal episódio apresenta e relata o processo criativo da designer e coreógrafa inglesa Es Devlin, a qual 
realiza grande parte de seus trabalhos na produção de cenários para peças de teatro e para palcos de shows musicais. Em um dos relatos Es relata o processo criativo de um cenário para a peça The Faith Healer 2016, uma série de monólogos melancólicos que se passam na lama e na chuva. Nesse caso especifico seu design está centrado na ideia de estimular sensações melancólicas na plateia, como um complemento as interpretações dos atores. Para tal ela projeta um palco em forma de cubo, e o circunda por uma cortina de chuva entre os atores e a plateia, que funcionava entre um ato e outro. Enquanto de um lado os atores vivenciavam sensações de desaparecem e aparecem por meio da "cortina" de chuva, a plateia tinha a sua disposição um interlúdio que permitia evocar uma tristeza itinerante e dessa forma vivenciar o conteúdo de cada monólogo. Com vista a essa discrição o que parece ter sido desenhado pela design inglesa é uma série de dinâmicas experienciais capazes de intensificar sensações estéticas nos espectadores, ou em outras palavras, ela projetou o para-raios e dessa forma estimulou a ocorrência de experiências de natureza estética, singular e intensamente afetiva, que se concretizam por conveniência, ou seja, estimulou a ocorrência das vivências.

\section{Considerações finais}

De maneira pragmática este artigo buscou apontar as bases para o pensamento de um novo nicho do design, o design de vivências. Para tal de início apontamos as definições do termo vivência e a comparamos com a noção de experiência, passando por conceitos que somados geraram o entendimento da mesmo como sendo: um tipo de experiência de natureza estética, singular e intensamente afetiva, que se concretiza por conveniência. Em seguida, com base em uma breve análise de alguns modelos visuais desenvolvidos por outros autores apontamos para os mecanismos que formam uma vivência. E por fim refletimos esses conceitos em uma possível práxis de um design de vivências.

Como desdobramentos aos pontos levantados neste artigo cabe levantar algumas questão que se mostram como caminhos férteis no raciocínio de um design de vivências. Por que o entendimento de um design de vivência seria importante para o campo do design? De início cabe apontar para a abertura desse tipo de experiência, com uma crescente valoração das interações estético-individuais em serviços e produtos de design. Em seguida a constatação feita por Larrosa (2012) da nebulosidade nas definições das bases da experiência. Este assunto ainda carece de desenvolvimento acadêmico, sendo o design um campo de estudo que está preocupado com as questões estéticas, um aprofundamento nesse tema se faz necessário. Outro possível desdobramento se encontra na seguinte questão: para que serviria a vivência ao design e aos designers? Como foi visto em alguns exemplos citados acima, a interação com os mecanismos da vivência teria a capacidade de fornecer ao designer matéria prima para os projetos de experiências que estimulariam determinadas sensações, além de fornecer um entendimento mais claro do efeito dessas experiências nos usuários.

Por ser um assunto fértil e ainda carente de reflexão, aprontamos para algumas lacunas nessa linha de estudo. Sendo a vivência um fenômeno não passível de manipulação, quais serias as possíveis metodologias capazes de produzir experiências férteis para a ocorrência de vivências verdadeiramente transformadoras? Como identificar os pontos de contatos que promovem a ocorrência de uma vivência em determinado indivíduo? Existe a possibilidade de classificar as vivências como mais ou menos transformadoras? Essas e outras perguntas podem ser feitas a partir da construção do raciocínio apresentamos neste artigo. Mas o que nos fica claro com esse estudo é que com a definição das bases teóricas que formam a natureza do fenômeno da vivência, existe a necessidade de levantar tais perguntas e buscar as resposta para as mesma. 


\section{For a design of experiencing}

Abstract: This article presents a brief exploratory study with the purpose of indicating some relational bases between the concept of experiencing and the field of design. In other words, our intention is to provide support for a design of experiencing.

The study allowed us to lay the groundwork for thinking about a new niche of design, the design of experiencing. To that end, we first set out the definitions of the term experiencing, based on a study developed on the philosopher Friedrich Nietzsche's thinking, and compare it with the notion of experience, passing through concepts that added to the understanding of the same as being: a type of Experience of aesthetic nature, singular and intensely affective, that is concretized by convenience. Then, based on a brief analysis of some visual models developed by other authors we point to the mechanisms that form an experience. And finally we reflect these concepts in a possible praxis of a design of experiencing.

Keywords: Experiencing; aesthetic; experience; service design;

\section{Referências bibliográficas}

ALMEIDA, R. 0 mundo, os homens e suas obras: filosofia trágica e pedagogia da escolha. Tese de livre docência pela Universidade de São Paulo, 2015.

BECCARI, M. Articulações Simbólicas: uma nova filosofia do design. Teresópolis, RJ: 2AB, 2016.

FERNANDES, M. Consciência, vivência e vida: um percurso fenomenológico. Revista da Abordagem Gestáltica, v. 16, n. 1, p. 29-41, 2010.

LINDSTRÖM, J. Meeting room design based on experience production and the creative process: a conceptual development of meeting rooms for the meeting industry. 2009.

LÖBACH, Bernd. Design industrial. São Paulo: Edgard Blücher, 2001.

MILECK, L. Modelo teórico-prático de co-criação para vivências: um estudo exploratório do design para vivencias. Dissertação de mestrado, Universidade Federal do Paraná, Programa de Pósgraduação em Design, Curitiba, Brasil,2016.

MORENTE, M. ; BENGOECHEA, J. Fundamentos de filosofia. Mestre Jou, 1970.

NIETZSCHE, F. Aurora. (Trad. Paulo César de Souza). São Paulo: Companhia das Letras, 2004.

PERNIOLA, M. A estética do século XX. Lisboa: Editorial Estampa, 1998.

TONETTO, L.; COSTA, F. Design Emocional: conceitos, abordagens e perspectivas de pesquisa. Strategic Design Research Journal, 2011, 4.3: 132-140.

VIESENTEINER, J. O conceito de vivência (Erlebnis) em Nietzsche: gênese, significado e recepção.

Kriterion: Revista de Filosofia, v. 54, n. 127, p. 141-155, 2013. 